\title{
Research Paper: Identification and Prioritization of Effective Factors on the Social Health of the El- derly Using DEMATEL and ISM Methods
}

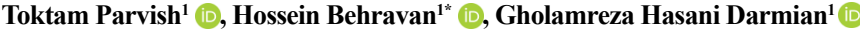 \\ 1. Department of Social Science, Faculty of Letters and Humanities, Ferdowsi University of Mashhad, Mashhad, Iran.
}

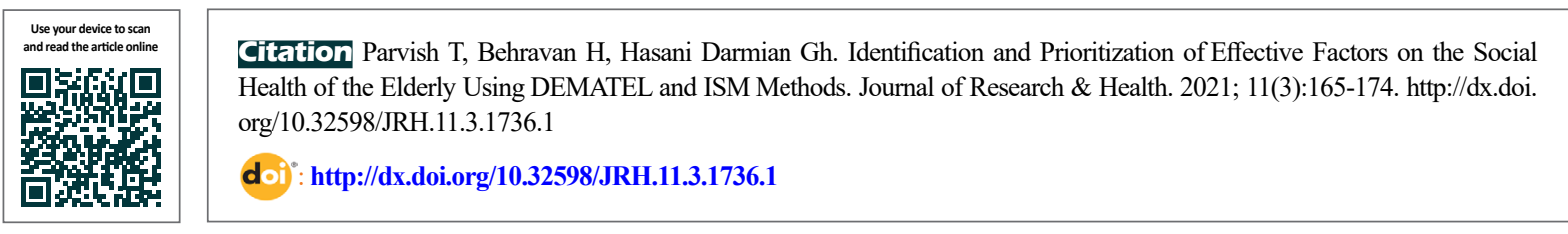

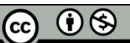

Article info:

Received: 17 Sep 2019

Accepted: 18 Dec 2019

Publish: 01 Jun 2021

\section{Keywords:}

Social determinants of health, Aging, Statistics as the topic

\section{A B S T R A C T}

Background: The number of elderly people is growing continuously. These people are more vulnerable to social harm, such as loneliness, depression, etc, on the eve of aging. Therefore, it is important to promote their social health indicators as factors influencing social development. Generally, the interactions of various factors affect social health. Thus, this study aimed to identify, prioritize, and assess the extent of the interactions between the factors affecting the elderly's social health.

Methods: The present study applied a combinatory research method, including two sections of qualitative and quantitative. In the qualitative section, factors that affected the elderly's social health were identified through the evaluation of 14 factors. In the quantitative section, the interpretive structural modeling and evaluation technique and decision-making test were used to evaluate factors and quantitatively analyze the relationships between factors, respectively. Besides, 12 experienced experts in the field of elderly health from the Deputy of Health of Khorasan Razavi province participated in this section.

Results: The results showed that among the factors studied, socioeconomic status, social capital, residence (home shelter), social support, and environmental factors were effective factors on the social health of the elderly. Also, leisure time, lifestyle, and social vitality were identified as affected factors or effects.

Conclusion: The researchers suggest that policymakers and specialists should consider prioritizing the causes and effects in the area of elderly's social health and pay particular attention and focus on the effective factors. Proper planning will create the ideal conditions for older people, reduce the economic burden of old age, and enhance social development and advancement in different fields.

\section{"Corresponding Author:}

Hossein Behravan, PhD.

Address: Department of Social Science, Faculty of Letters and Humanities, Ferdowsi University of Mashhad, Mashhad, Iran.

Phone: +98 (915) 3139477

E-mail: behravan@um.ac.ir 


\section{Introduction}

$\mathbf{T}$

he growing population is one of the issues facing most countries, particularly Iran. According to Bloom et al., Iran ranks third after the UAE and Bahrain, in terms of accelerated population growth [1]. Thus, although growth influences the aging phenomenon, neglecting its consequences can pose a serious obstacle to development.

For the elderly, the most important issue is to pay attention to their health. To promote active and healthy aging, it is necessary to take into account all the aspects of the health of the elderly. As specified by the World Health Organization, it applies not only to physical and psychological dimensions but also to the well-being of the entire physical, mental, and social aspects. In conceptualizing and measuring social health, Keyes as one of the leading sociologists evaluates one's status and performance in society. He believes that people are socially healthy when they feel that they belong to a group like neighborhood, friends, or community as a whole; feel good about others; have trust in their integrity and diligence; and feel comfortable with others. They are active community members that can provide important things to other people. Healthy people are hopeful about society's state and future and can identify society's potentials. Also, these individuals consider their personal lives meaningful and set goals for their lives [2]. The findings of social health research show that exposure to this trend contributes to the promotion of the social life indices, such as social capital, social security, social stability, social support, social participation, etc [3-5].

Thus, studying and identifying the factors that affect the elderly's social health can create a favorable time for them, reduce the economic burden of aging to some extent, and provide social development and progress in various fields.

Research results to date indicate that the direct and indirect impact on the different factors of social health varies depending on different circumstances. Moreover, although the variables were analyzed together, the relationship between the influences and the effects of the causes was compensated little. Consequently, the paper's novelty includes not only measuring the diversity of factors but also introducing a new way to interact with factors. Therefore, the main research questions were as follows:

1. What are the most significant factors that affect older people's social well-being from the experts' perspective?
2. What are the extent and level of impact on social health prioritized?

\section{How do these factors affect each other?}

\section{Methods}

This research was descriptive-analytical in terms of purpose and included implementation and data collection. The research method was a synthesis of qualitative and quantitative components. The former aimed to classify factors affecting the elderly's social health, and the latter included a quantitative analysis to evaluate and examine the relationships and connections between these factors, using two techniques of Interpretive Structural Modeling (ISM) and evaluation method and decision-making test (DEMATEL). Besides, two different questionnaires were developed for this purpose. In a questionnaire designed for ISM, experts were asked to identify the type of relationship between the driving and dependent power factors. Also, another questionnaire designed for DEMATEL analysis asked experts to quantify the severity of each factor.

The validity of the questionnaire was used to evaluate the validity of the content. Five experts in the field of university and elderly health contributed to the layout of the questionnaires, the appropriateness of how to model the questionnaires, and the consistency and comprehensibility of the variables of the survey.

The Cronbach alpha coefficient was used to test the questionnaires' accuracy. The results were obtained as 0.86 and 0.89 for the ISM and DEMATEL methods, respectively, showing the questionnaires' accuracy.

This type of study initially investigates the background of the scientific topic. Thus, a literature search was conducted in IRANDOC (Iranian Scientific Information and Documentation Research Center), the Iranian Jihad Scientific Database, and the Iranian Journal of Medical Sciences Database for accessible studies and research related to social health. The search results were limited for articles with the keyword of social health. For example, out of a list (Jahaddaneshgahi Database) of 350366 articles, only 364 were dedicated to the elderly (ie, $10 \%$ of them). Also, out of these 364 articles, only 29 were related to the field of social health (ie, $8 \%$ of social health studies).

The ISM method was used to specify the degree of interacting effects between the factors. This method helps identify the internal relationships between factors. In other words, ISM is a good technique to analyze one fac- 
tor's influence on other factors and can help prioritize and determine the level of factors in a system. The steps to implement the ISM method were as follows:

A, Structural self-interaction matrix: The factors identified were examined in pairs to form the matrix, and the relationship between them was determined using $\mathrm{V}, \mathrm{A}$, $\mathrm{X}$, and $\mathrm{O}$ symbols.

- Symbol V: If element $\mathrm{i}$ affects element $\mathrm{j}$ but element $\mathrm{j}$ does not affect element $\mathrm{i}$.

- Symbol A: If element i does not affect element $\mathrm{j}$ but element $\mathrm{j}$ affects element $\mathrm{i}$.

- Symbol X: If both elements affect each other.

- Symbol O: If two elements do not affect each other.

B, Reachability matrix construction: The rules for converting the structural self-interaction matrix into the reachability matrix are as follows:

- If the element $(i, j)$ in the structural self-interaction matrix is equal to $\mathrm{V}$, the element $(i, j)$ in the reachability matrix is 1 and the element $(j, i)$ is 0 .

- If the element $(i, j)$ in its structural self-interaction matrix is equal to $A$, the element $(i, j)$ in the reachability matrix is 0 and the element $(j, i)$ is 1 .

- If the element $(i, j)$ in the structural self-interaction matrix is equal to $X$, the element $(i, j)$ in the reachability matrix is 1 and the element $(\mathrm{j}, \mathrm{i})$ is 1 .

- If the element $(i, j)$ in the structural self-interaction matrix is equal to $\mathrm{O}$, the element $(\mathrm{i}, \mathrm{j})$ in the reachability matrix is 0 and the element $(j, i)$ is 0 .

After the development of the initial reachability matrix, the matrix transitivity should be examined. That is if factor I affects factor $\mathrm{J}$ and factor $\mathrm{J}$ affects factor $\mathrm{K}$, factor I will affect factor $\mathrm{K}$. After the transfer matrix, the final reachability matrix is obtained. The transferability condition is that there must be a relationship between two factors, that is, the matrix layer is one, and so if the matrix size is zero, that layer is changed to one.

C, Partitioning the factors to different levels: The effect is from bottom to top in this model. The higher the component that affects the other factors, the lower the level, and the higher the effect on the other factors, the higher the model's value. It is necessary to define the following categories to describe the factors.
- Reachability set for each element i: Contains the elements that affect element i plus element $\mathrm{i}$.

- Antecedent sets for each element i: Contains the factors that affect element $\mathrm{i}$ plus element $\mathrm{i}$.

- Subscription set for each element i: Subscription between the reachability and antecedent sets.

D, The structural model interpretation of factors affecting elderly social health: The model is drawn after when all factors have been categorized and their location in the causal model determined.

E, The MICMAC analysis: This study aims to identify variables based on their power to drive and rely on. The variables are classified into four categories:

- The first class is autonomous, that is, factors with a high degree of poor driving power and low dependency.

- The second cluster includes those barriers that have weak driving power and strong dependence.

- The th ird category consists of barriers with both strong driving power and dependence.

- The fourth category includes driving factors that have strong driving power and weak dependence.

Final $1 y$, DEMATEL will quantitatively display the strength of interactions, the relationships between factors, and the dependence and independence of factors in one number. This approach describes the cause-andeffe $\mathrm{c} t$ relationships between factors that affect social health. The DEMATEL method's steps and findings are as follows:

A: Creating a matrix of direct relationships: First, Bob created a measuring system to assess the causes and effects of the interaction relationships. Then, Linn and $\mathrm{Wu}$ in 2008 divided the levels into four classes, with numbers $0,1,2$, and 3 showing no, low, medium, and very high relevance levels, respectively. The opinions of 12 experts were used to calculate the simple average of expert opinions on each variable pair as the degree of relationship between the factors, the production of which is a square matrix showing the direct relationships between the factors. Since the elements do not directly affect the original diameter, the elements are zero.

B: The normalization coefficient is the average of the largest row sum and the total mean column sum of the matrix derived from the following relationship. 


\section{Results}

After a comprehensive review of the research, the most important factors affecting aging and social health were identified as follows:

1. Social support: Social support is the degree of affection, companionship, and attention of family members, friends, and others [6]. The findings of various studies confirm the social health effect of social support [3-5, 7-9].

2. Environmental factors: This includes the value of the environment in which people live (appearance, functionality, and aesthetics). Environmental quality is assessed by factors, such as the quality of service accessibility, inc luding health services; housing; shopping centers; recreational facilities; and physical environment, such as the availability of green space, the quality of sidewalks, traffic, etc. Results of Rollero and De Piccoli, Alidoust et al., Eibich et al. showed the impact of environmental factors on social health [10-12].

3. Leisure: Domaziyeh believes that leisure is a set of act ivities that people pursue with a passion for work, family, and social work to rest, develop their knowledge or enhance their personality or for the emergence of talent, creativity, and ultimately free participation in society [3]. Leisure time is measured by indicators, such as study, travel, sports, cinema and theater, crafts, creativity television watching and listening, etc. The results of Amir Ahmadi and Amini Asadabadi, Hezar Jaribi and Arfaee showed the social health impact of leisure time [13, 14].

4. Socioeconomic status: This refers to the individual's group ranking. In other words, the achievement of a norm by an individual in comparison with the current ave rage expectations of cultural attributes, effective employment, material possessions, and personal group activity participation [9]. Zahediasl and Darwishifard, Seyfzadeh, Farzane and Alizade, Tajeddin, Sam Aram, and Sharbatiyan and Tavafi have accepted the impact of socioeconomic status on social health [3-5, 15-17].

5. Lifestyle: This factor includes objective and subjective behavioral patterns that the individual or community cho oses to symbolically differentiate themselves from oth er individuals or groups. What is represented and distinguished by this symbol may include individuality, identity, social status or spiritual mechanism, and mental habits [18]. Some aspects of lifestyle include eating (traditional or fast food), cooking, leisure, and working hours (exercising or resting at home). The study results of Jenaabadi and Parsamehr and Rasoulinezhad have confirmed the effect of lifestyle on social health $[19,20]$.

6. Social capital: According to Bourdieu, social capital is the accumulation of actual and potential resources that are related to having a relatively stable network of more or less institutionalized relationships of mutual acquaintance or, in other words, the membership of a group for each. A group provides its members with the support of a collective capital that entitles them to credit. Bourdieu's position on social capital has focused on the extent of links or social networks [14]. Amini Rarani et al., Vosoughi et al., Kosheshi et al. have shown that higher social capital leads to the promotion of social health [14, 21-23].

7. Religion: According to Durkheim, religion refers to the collection of behaviors, beliefs, and attitudes related to the field of faith, including religious concepts and religious practices. Therefore, the religiosity of people can be measured in terms of their set of religious beliefs and attitudes and the degree to which they are adhered to and acted upon. Jenaabadi, Edrisi et al., Mirza Mohammadi et al. showed a significant effect of religiosity on social health $[19,24,25]$.

8. Social security: Social security has to do with the areas of confidentiality related to other members of society, organizations, and government. In other words, it refers to the degree to which individuals in their daily lives are emotionally and psychologically comfortable and immune to other people's potential dangers and abuse in society [26]. So, being able to get out of the house peacefully day and night with no intimidation is one of the social security measures of society. The study results of Tajeddin, Sam Aram, Edrisi et al. Feghhi Farahmand and Zanjani, Fallahi and Kaffash showed the impact of social security on social health $[15,16,24,27,28]$.

9. Social trust: Trust is defined as an individual and personality trait that is closely related to concepts, such as loyalty, honesty, and altruism. The results of research by Edrisi et al., Zaki and Khoshouei confirm a significant relationship between social trust and social health [24, 29]

10. Social vitality: Winhowon (1993) defined happiness as the degree or extent of one's judgment about the utility of his/her quality of life. In other words, it means how much individuals love their lives. The results of several studies $[22,29]$ confirmed the effect of social vitality on social health.

11. Life satisfaction: Diener et al. (1985) described life satisfaction as the subjective evaluation of one's over- 
all quality of life or some aspect of one's life [30]. The Research results of Afshani and Shiri Mohammadabad show a significant and direct relationship between life satisfaction and social health so that social health increases with increasing life satisfaction [31].

12. Quality of life: According to the World Health Organization, quality of life is peoples 'sense of well-being, a feeling of comfort in the satisfaction of the various aspects of life, which are important to them. The research results of Hosseini, Majdi, and Hasani indicate the impact of quality of life on social health [32].

13. Social participation: It includes various types of individual and group actions to intervene in the determination of one's self and society and influence public decision-making processes. Examples include membership in organizations, such as mobilization, sports teams, ceremonies, celebrations, etc [33]. The research of Nikvarz and Yazdanpanah has confirmed the effect of social participation on social health [34].

14. Residence: Residence means the place of residence of an elderly person, whether an elderly person lives at home or in a nursing home. The results of Sayar and Babakhanian indicated that the average social health of the elderly residing in the elderly home was less than the average social health of the elderly in the home [7]. Pasha et al. also noted a significant difference in general health between the elderly living in the nursing home and those living in the household [35].

Findings from ISM show the first step in implementing this method. As stated in the model explanation, this step includes the development of a self-interaction structural matrix. According to Table 1, the matrix uses symbols to describe the variables' internal relationships.

The reachability matrix was obtained by converting the symbols to numbers 0 and 1 , then, the factors were partitioned in the next step. How to partition factors is to remain at level 1 for each item that has the same reachability and subscription collection. This element was then excluded from the set of factors and the procedure was carried out to partition all the factors for other factors (Table 2).

After the factors were partitioned, the structural model of interpreting factors affecting the elderly's social health was drawn. Factors, such as socioeconomic status, social capital, the place of residence (residents/non-residents in the elderly home), social support, environmental factors, and religiosity are established as high-driving barriers.

Table 1. Structural self-interaction matrix

\begin{tabular}{|c|c|c|c|c|c|c|c|c|c|c|c|c|c|c|c|}
\hline & Factors & 14 & 13 & 12 & 11 & 10 & 9 & 8 & 7 & 6 & 5 & 4 & 3 & 2 & 1 \\
\hline 1 & Social support & A & $\mathrm{x}$ & V & $\mathrm{v}$ & $\mathrm{v}$ & V & v & 0 & $x$ & $\mathrm{~V}$ & $x$ & v & 0 & 0 \\
\hline 2 & Environmental factors & A & V & V & $\mathrm{v}$ & $\mathrm{v}$ & V & v & 0 & 0 & v & 0 & v & 0 & \\
\hline 3 & Leisure & A & $\mathrm{x}$ & $\mathrm{x}$ & $x$ & $x$ & A & A & A & A & $x$ & $A$ & 0 & & \\
\hline 4 & Socioeconomic situation & $\mathrm{V}$ & V & V & $\mathrm{v}$ & v & $\mathrm{O}$ & 0 & 0 & V & V & 0 & & & \\
\hline 5 & Life style & A & $\mathrm{x}$ & $\mathrm{x}$ & A & $x$ & $\mathrm{O}$ & A & A & 0 & 0 & & & & \\
\hline 6 & Social capital & V & $x$ & V & V & $\mathrm{V}$ & V & $\mathrm{O}$ & $\mathrm{O}$ & 0 & & & & & \\
\hline 7 & Religion & 0 & V & V & $\mathrm{v}$ & $\mathrm{v}$ & V & 0 & 0 & & & & & & \\
\hline 8 & Social security & 0 & $\mathrm{x}$ & $x$ & $\mathrm{v}$ & V & V & 0 & & & & & & & \\
\hline 9 & Social trust & 0 & V & A & $x$ & $x$ & 0 & & & & & & & & \\
\hline 10 & Social vitality & $A$ & $x$ & $x$ & $x$ & 0 & & & & & & & & & \\
\hline 11 & Life satisfaction & A & A & $x$ & 0 & & & & & & & & & & \\
\hline 12 & Quality of life & A & $\mathrm{x}$ & 0 & & & & & & & & & & & \\
\hline 13 & Social participation & A & 0 & & & & & & & & & & & & \\
\hline 14 & Residence place & 0 & & & & & & & & & & & & & \\
\hline
\end{tabular}


Table 2. Partitioning the first level factors

\begin{tabular}{ccccc}
\hline Factors & Reachability Set (Driving) & Antecedent Set (Dependency) & Subscription Set & Level \\
\hline 1 & $1,3,4,5,6,8,9,10,11,12,13$ & $1,4,6,13$ & $1,4,6,13$ \\
\hline 2 & $2,3,5,8,9,10,11,12,13$ & 2,14 & 1 \\
\hline 3 & $3,5,10,11,12$ & $1,2,3,4,5,6,7,8,9,10,11,12,13,14$ & $3,5,10,11,12$ \\
\hline 4 & $1,3,4,5,6,10,11,12,13,14$ & 1,4 & 1,4 \\
\hline 5 & $3,5,10,12,13$ & $1,2,3,4,5,7,8,10,11,12,13,14$ & 1 \\
\hline 6 & $1,3,6,9,10,11,12,13$ & $3,5,10,12,13$ & \\
\hline 7 & $3,5,7,9,10,11,12,13$ & $1,4,6,13$ & $1,6,13$ \\
\hline 8 & $3,5,8,9,10,11,12,13$ & 7 & 7 \\
\hline 10 & $3,9,10,11,13$ & $1,2,8,12,13$ & \\
\hline 13 & $3,5,9,10,11,12,13$ & $1,2,3,4,5,6,7,8,9,10,11,12,13,14$ & $3,5,9,10,11,12,13$ \\
\hline 14 & $3,5,9,10,11,12,13$ & $1,2,3,4,6,7,8,9,10,11,12,13,14$ & $3,9,10,11,12,13$ \\
\end{tabular}

Factors, such as social security, quality of life, social confidence, and social engagement have been identified as intermediate factors with moderate effects. Also, factors, such as life satisfaction, leisure time, lifestyle, and social vitality have been identified as obstacles with high dependence. Relationships among factors suggest the importance of providing the basis for improving the elderly's social health. For example, an elderly person's socioeconomic status affects his/her social capital and residence (Figure 1).

Ultimately, the variables are classified by driving power and dependency power through the MICMAC analysis. As can be seen, the influences of social support, socioeconomic status, social security, social capital, the place of residence, and environmental and religious factors have the strength of leisure and driving force, lifestyle, and social trust (Figure 2).

Findings from DEMATEL are shown in this approach; causal relationships have been established between factors that affect social health. Based on the results of Table 3 , factors can be investigated from two perspectives. The first view is to what extent one factor has to do with other factors. For example, environmental factors, religiosity, and place of residence (home or the elderly home) have some relation with other factors. Factors, such as social security, social trust, leisure, social capital, and lifestyle are moderately related, and factors, such as social participation, socioeconomic status, social support, social vitality, quality of life, and life satisfaction have the highest relationship with other factors.

The second point of view is the influence of quantitatively calculated factors. Variables, such as environmental factors, socioeconomic status, religiosity, the place of residence, social support, social capital, social security, and social participation have been described as the barriers with high driving power. Besides, factors, such as leisure time, satisfaction with life, quality of life, social vitality, lifestyle, and social trust have been identified as the barriers with high dependency power (Figure 3).

\section{Discussion}

Social well-being is one of the most important issues of sustainable development and is placed at the center of social economy and social well-being. Elderly people are more vulnerable to feelings of depression, social isolation, and other social traumas at their retirement. Therefore, it is necessary to know the factors affecting the elderly's social health. Reviewing the research lit- 
Table 3. Row and column sum and degree of influence

\begin{tabular}{|c|c|c|c|c|c|}
\hline & Factors & Di & $\mathbf{R j}$ & (Di+Rj) & (Di-Rj) \\
\hline 1 & Social support & 6.716 & 5.911 & 12.627 & 0.805 \\
\hline 2 & Environmental factors & 5.401 & 4.117 & 9.518 & 1.284 \\
\hline 3 & Leisure & 5.051 & 6.440 & 11.491 & -1.389 \\
\hline 4 & Socioeconomic situation & 6.805 & 5.586 & 12.391 & 1.220 \\
\hline 5 & Life style & 5.491 & 6.347 & 11.837 & -0.856 \\
\hline 6 & Social capital & 5.986 & 5.549 & 11.535 & 0.438 \\
\hline 7 & Religion & 5.550 & 4.419 & 9.969 & 1.131 \\
\hline 8 & Social security & 5.627 & 5.375 & 11.002 & 0.252 \\
\hline 9 & Social trust & 5.459 & 6.020 & 11.479 & -0.561 \\
\hline 10 & Social vitality & 5.865 & 6.944 & 12.810 & -1.079 \\
\hline 11 & Life satisfaction & 5.903 & 7.169 & 13.073 & -1.266 \\
\hline 12 & Quality of life & 5.871 & 6.976 & 12.846 & -1.105 \\
\hline 13 & Social participation & 6.071 & 6.037 & 12.108 & 0.034 \\
\hline 14 & Residence & 6.021 & 4.928 & 10.949 & 1.093 \\
\hline
\end{tabular}

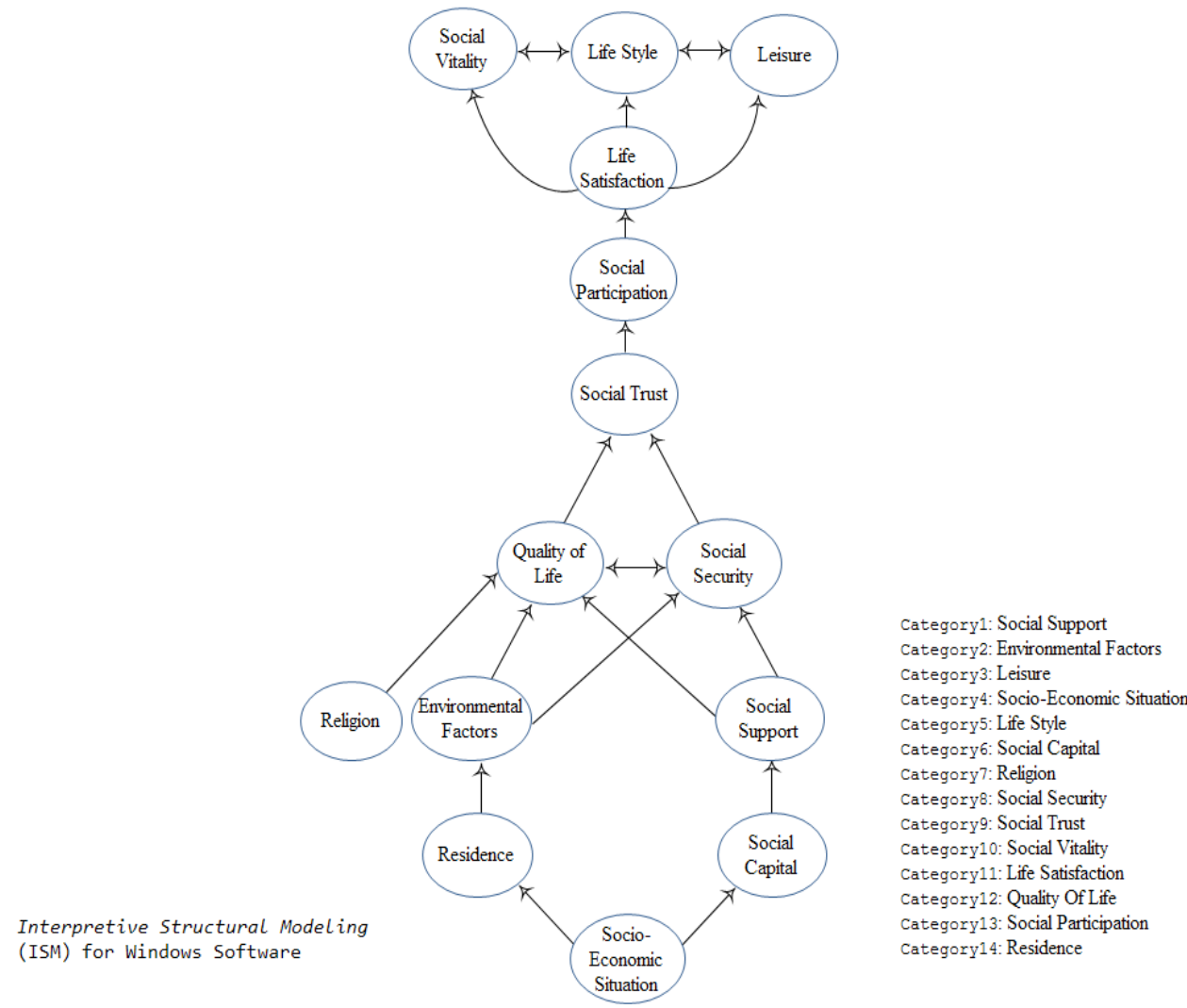

Figure 1. Interpretative structural model of factors affecting social health of the elderly 


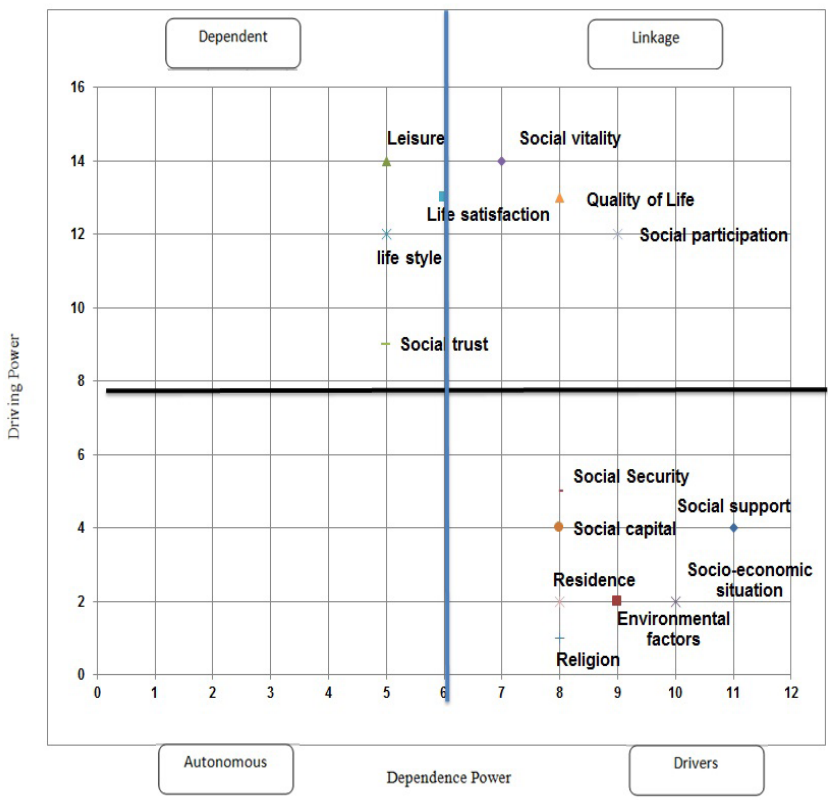

Figure 2. MICMAC analysis diagram

mRA

erature on social health, this report identified 14 factors affecting the social health of the elderly. Then, the interpretive conceptual model approach was used to prioritize the factors, and the evaluation and decision-making test was used to assess the importance and frequency between the factors of the quantitative relationships. The reason for using both ISM and DEMATEL is that the ISM method only determines the level of the influence of factors on each other and helps to identify the internal relationships among the factors. In other words,
ISM is a good technique for analyzing one factor's influence on other factors and can help prioritize and determine the level of factors in a system, while DEMATEL is capable of doing so. It quantifies the strength of the interactions and relationships between the factors and shows how many factors affect each other. In this study, the prioritization of DEMATEL confirmed the prioritization of the ISM method. Thus, based on the qualitative part of the research, the review analysis, and the quantitative part of the research (ie, the use of inter-

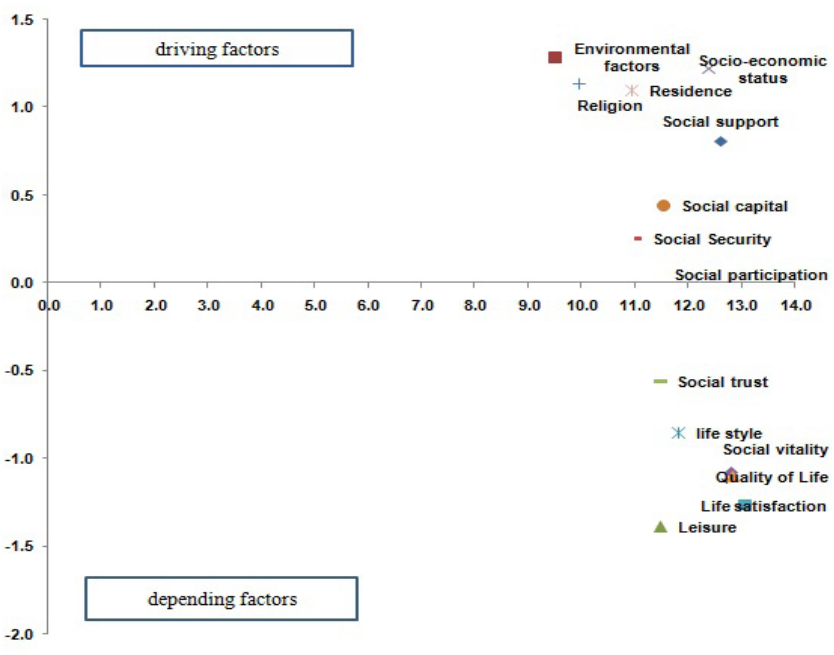

Figure 3. Degree of influence among factors affecting social health of the elderly 
pretive systemic modeling methods and the assessment and decision-making check) it is concluded that the basic elderly socioeconomic status, religiosity, and residency are factors in promoting and improving the social health of the elderly.

The limitations of this study include focusing on previous studies, which resulted in identifying only 14 effective factors, while other factors may have been neglected. Furthermore, the results of this study are highly dependent on the opinion of the questioned experts and may change due to the relevant statistical sample. Nevertheless, it is critical that the reviewers agree on the validity of the findings.

\section{Conclusion}

Using the findings of the ISM helps policymakers and planners in geriatric health obtain an accurate picture of the factors affecting the elderly's social health and can improve the elderly's social health by considering the most important and effective factors. Also, DEMATEL quantitatively analyzes the relationship and severity of affectivity and effectiveness between factors and helps planners and professionals to better focus on causal factors and realize them. Finally, this combination would improve older people's social health.

\section{Ethical Considerations}

\section{Compliance with ethical guidelines}

This study was approved by the Ethics Committee of the Ferdowsi University of Mashhad (Code: IR.UM. REC.1398.044).

\section{Funding}

This study was extracted from the $\mathrm{PhD}$. dissertation of the first author at the Department of Social Science, Faculty of Letters and Humanities, Ferdowsi University of Mashhad.

\section{Authors' contributions}

Data collection and analysis: Toktam Parvish; Manuscript preparation: Toktam Parvish, Hossein Behravan; Study design, final approval: All authors.

\section{Conflict of interest}

The authors declared no conflict of interest.

\section{Acknowledgments}

We want to thank and appreciate all the elderly health experts at the Khorasan Razavi Health Center who replied to the questions.

\section{References}

[1] Bloom DE, Boersch-Supan A, McGee P, Seike A. Population aging: Facts, challenges and responses [Internet]. 2011 [Updated 2011 May]. Available from: http://cdn1.sph.harvard. edu/wp-content/uploads/sites/1288/2013/10/PGDA_ WP_71.pdf

[2] Keyes CLM. Social well-being. Soc Psychol Q. 1998; 61(2):121-40. [DOI:10.2307/2787065]

[3] Zahediasl M, Darvishifard AA. [Social factors influencing the social health of the elderly in Kouhdasht (Persian)]. Soc Dev Welf Plan. 2016 ; 8(26):9-32. [DOI:10.22054/QJSD.2016.4880]

[4] Seyfzadeh A. [Investigating the elders' social health and its related factors: A case study of Azarshahr city (Persian)]. J Geriatr Nurs. 2015; 1(4):95-106. https://jgn.medilam.ac.ir/ browse.php?a_id=135\&sid=1\&slc_lang=en

[5] Farzane S, Alizade S. [Study in social determinants on social health among older people in Babol town (Persian)]. Q J Socio Cult Dev Stud. 2013; 2(1):183-208. http://journals.sabz.ac.ir/ scds/article-1-66-en.html

[6] Golabi F. [Species of Leisure and its impact on youth's social health (Persian)]. J Economic Dev Sociol. 2013; 2(2):121-69. https:// sociology.tabrizu.ac.ir/article_3142.html

[7] Sayar S, Bababkhanian M. [Comparing the social health status among the older people living at home and those living in old people's home (Persian)]. J Isfahan Med Sch. 2016; 34(400):1128-33. http://jims.mui.ac.ir/index.php/jims/article/view/6753

[8] Hosseini Zare SM, Movahed E, Pourreza A, Rahimi Foroshani A. The effect of social support on the health of the elderly in Tehran. J Hosp. 2015; 13(4):115-21. http://jhosp.tums.ac.ir/ article-1-5470-en.html

[9] Khalili F, Sam SH, Sharifirad GH, Hassanzadeh A, Kazemi M. [The Relationship between Perceived Social Support and Social Health of Elderly (Persian)]. Journal of Health System Research. 2011; 7(6):1216-25. https://hsr.mui.ac.ir/article1-293-ne.html

[10] Rollero C, De Piccoli N. Does place attachment affect social well-being? Eur Rev Appl Psychol. 2010; 60(4):233-8. [DOI:10.1016/j.erap.2010.05.001]

[11] Alidoust S, Holden G, Bosman C. Urban environment and social health of the elderly: A critical discussion on physical, social and policy environments. Athens J Health. 2014; 1(3):169-80. [DOI:10.30958/ajh.1-3-1]

[12] Eibich P, Krekel C, Demuth I, Wagner GG. Associations between neighborhood characteristics, well-being and health vary over the life course. Gerontology. 2016; 62(3):362-70 [DOI:10.1159/000438700] [PMID] 
[13] Amir Ahmadi R, Amini Asadabadi M. [The study of the underlying factors on the social health of the elderly in 2017 (Persian)]. Paper presented at: The $4^{\text {th }}$ National Conference on the New Research of Humanities and Social Studies in Iran 6 Febrruary 2017; Qom, Iran. https://www.civilica.com/ Paper-SHCONF04-SHCONF04_032.html

[14] Hezar Jaribi J, Arfaee Einodin R. [Leisure time and social health (Persian)]. Soc Dev Welf Plan. 2012; 4(10):39-64. http:/ / qjsd.atu.ac.ir/article_3532.html

[15] Tajeddin MB. [Determinants of social health of citizens in district 12 of Tehran (Persian)]. Soc Dev Welf Plan. 2018; 9(32):61-96. [DOI:10.22054/QJSD.2017.8426]

[16] Sam Aram E. [Investigating the relationship between social health and social security with emphasis on communitybased policing approach (Persian)]. J Soc Ord. 2009; 1(1):9-29. https:/ / www.sid.ir/fa/journal/ViewPaper.aspx?id=144055

[17] Sharbatiyan MH, Tavafi P. [Sociological study of social wellbeing feeling criteria of Mashhad's citizenry (Persian)]. Motaleate Farhangi- Ejtemaei Khorasan. 2016; 10(4):115-37. http://www. farhangekhorasan.ir/article_40832.html

[18] Jabaran MR. [Conceptual analysis of lifestyle (Persian)]. Qabasat. 2017; 20(75):173-87. http://qabasat.iict.ac.ir/article_17771_ en.html

[19] Jenaabadi $H$. [The study of the relationship between Islamic lifestyle and job satisfaction and social health of high school teachers in Zahedan (Persian)]. J Appl Couns. 2017; 7(2):45-54. http://jac.scu.ac.ir/article_13353_en.html

[20] Parsamehr M, Rasoulinezhad SP. [The study of the relationship between lifestyle and social health among people of Talesh City (Persian)]. Q J Soc Dev. 2015; 10(1):35-66. http:// qjsd.scu. ac.ir/article_11936_en.html

[21] Amini Rarani M, Mousavi MT, Rafiey H. [Correlation of social capital with social health in Iran (Persian)]. Soc Welf Q. 2011; 11(42):203-28. http:/ / refahj.uswr.ac.ir/article-1-734-en.html

[22] Vosoghi M, Mahdavi SMS, Rahmani khalili E. [A study on the effect of social capital on social health considering social happiness and social support (Persian)]. Iran J Soc Probl. 2013; 4(2):23563. https://ijsp.ut.ac.ir/article_52144.html

[23] Kosheshi M, Mirzaei M, Pourreza A, Hassani Darmian GR. [The effect of social capital on the health of the elderly with 60 or more years of age in mashhad urban districts (Persian)]. J Soc Sci 2016; 13(1):109-29. [DOI:10.22067/JSS.V13I1.52668]

[24] Edrisi A, Sheikhdadzadeh L, Barzgari M. [Religions rules and instituation have huge responsibiliy in improvig caltural and moral standards of the society (Persian)]. J Med Counc Iran. 2016; 34(3):215-32. https://www.sid.ir/fa/journal/ViewPaper aspx?id=305434

[25] Mirzamohammadi MH, Farmahini Farahani M, Esfandyari S. [Investigating the role of religious education in individual and social health. Iran J Knowl Stud Islam Univ. 2011; 15(2):20-45. http://ensani.ir/fa/article/265534

[26] Mazlum Khorasani M, Ata E. [Investigating women's sense of social security and factors influencing it in Mashhad in 2006 (Persian)]. J Soc Sci. 2010; 7(2):219-51. [DOI:10.22067/JSS.V0I0.15834]

[27] Fegh-hi Farahmand N, Zanjani S. [The examination of the relationship between social capital and health and social security
(Persian)]. J Soc Stud. 2011; 3(10):99-112. http://jss.iaut.ac.ir/ article_521045_en.html

[28] Fallahi A, Kaffash M. [The effect of social development on social health in Tehran metropolis (Persian)]. J Iran Soc Dev Stud. 2018; 10(2):59-72. http://jisds.srbiau.ac.ir/article_12365.html

[29] Zaki MA, Khoshouei M. [Factors affecting social well-being of the residents of the city of Isfahan (Persian)]. Urban Stud. 2013; 3(8):79-108. http://urb.dehaghan.ac.ir/article_667847. $\mathrm{html}$ lang=fa

[30] Sharbatiyan MH, Imeni N. [A sociological analysis of social health of youth and factors affecting it (case study: 18- to 30-yearold citizens of qaen city)(Persian)]. J Appl So. 2018; 29(1):167-88. [DOI:10.22108/JAS.2017.75233.0]

[31] Afshani AR, Shiri Mohammadabad H. [The study of relationship between life satisfaction and social health of Yazd city women (Persian)]. J Toloo-e-Behdasht. 2016; 15(2):34-44. http:// tbj.ssu.ac.ir/article-1-2193-en.html

[32] Hosseini A, Majdy A, Hassani G. [Investigating the role of social support on the quality of life of the elderly in Mashhad in 2014 (Persian)]. J Gerontol. 2016; 1(2):10-8. [DOI:10.18869/ acadpub.joge.1.2.10]

[33] Golabi F, Akhshi N. [Social happiness and social participation (Persian)]. J Appl Soc. 2015; 59(3):139-60. http://jas.ui.ac. ir/article_18407.html

[34] Nikvarz T, Yazdanpanah L. [Relationship between social factors and social health among students of Shahid Bahonar University of Kerman (Persian)]. J Applied Soc. 2015; 26(3):99116. http://jas.ui.ac.ir/article_18405.html

[35] Pasha GH, Safarzadeh S, Mashak R. [General health and social support in two groups of elderls living in nursing homes and with families (Persian)]. J Fam Res. 2007; 3(9):503-17 https://www.sid.ir/fa/journal/ViewPaper.aspx?ID=73162 